\title{
Acanthocephalan size and sex affect the modification of intermediate host colouration
}

\section{Journal Article}

Author(s):

Benesh, D. P.; Seppälä, O.; Valtonen, E. T.

Publication date:

2009

Permanent link:

https://doi.org/10.3929/ethz-b-000021580

Rights / license:

In Copyright - Non-Commercial Use Permitted

Originally published in:

Parasitology 136(8), https://doi.org/10.1017/S0031182009006180 


\title{
Acanthocephalan size and sex affect the modification of intermediate host colouration
}

\author{
D. P. BENESH${ }^{1}$, O. SEPPÄL $\ddot{A}^{2}$ and E. T. VALTONEN ${ }^{3}$ \\ ${ }^{1}$ Department of Evolutionary Ecology, Max-Planck-Institute for Evolutionary Biology, August-Thienemann-Strasse 2, \\ 24306 Plön, Germany \\ ${ }^{2}$ EAWAG, Department of Aquatic Ecology, and ETH-Zürich, Institute of Integrative Biology, Überlandstrasse 133, \\ 8600 Dübendorf, Switzerland \\ ${ }^{3}$ Department of Biological and Environmental Science, POB 35, FI-40014 University of Fyväskylä, Finland
}

(Received 5 Fanuary 2009; revised 10 February, 10 March and 16 March 2009; accepted 16 March 2009; first published online 19 May 2009)

\section{SUMMARY}

For trophically transmitted parasites, transitional larval size is often related to fitness. Larger parasites may have higher establishment success and/or adult fecundity, but prolonged growth in the intermediate host increases the risk of failed transmission via natural host mortality. We investigated the relationship between the larval size of an acanthocephalan (Acanthocephalus lucii) and a trait presumably related to transmission, i.e. altered colouration in the isopod intermediate host. In natural collections, big isopods harboured larger worms and had more modified (darker) abdominal colouration than small hosts. Small isopods infected with a male parasite tended to have darker abdominal pigmentation than those infected with a female, but this difference was absent in larger hosts. Female size increases rapidly with host size, so females may have more to gain than males by remaining in and growing mutually with small hosts. In experimental infections, a large total parasite volume was associated with darker host respiratory operculae, especially when it was distributed among fewer worms. Our results suggest that host pigment alteration increases with parasite size, albeit differently for male and female worms. This may be an adaptive strategy if, as parasites grow, the potential for additional growth decreases and the likelihood of host mortality increases.

Key words: Acanthocephala, Asellus aquaticus, cystacanth, host exploitation, host phenotype manipulation, intermediate host, larval life history, sexual dimorphism, trophic transmission.

\section{INTRODUCTION}

For trophically transmitted parasites, infectivity to the next host in the life cycle is only achieved at a certain developmental stage. Consequently, any parasite traits related to transmission, such as manipulation of host phenotype (reviewed by Moore, 2002; Thomas et al. 2005), should be expressed only after some degree of infectivity is achieved (e.g. Bethel and Holmes, 1974; Poulin et al. 1992; Pulkkinen et al. 2000; Seppälä et al. 2005; Franceshi et al. 2008). However, developing to an infective stage does not necessarily indicate that the probability of parasite establishment in the next host is at a fixed level. Invasion success typically varies among infective-stage individuals with larger parasites often faring better (Rosen and Dick, 1983 ; Steinauer and Nickol, 2003). Large larval parasites may also have other fitness advantages, such as a shorter developmental time to maturity or higher adult fecundity (Parker et al.

* Corresponding author: Department of Evolutionary Ecology, Max-Planck-Institute for Evolutionary Biology, August-Thienemann-Strasse 2, 24306 Plön, Germany. Tel: +494522763258; fax: +494522763310. E-mail: benesh@evolbio.mpg.de
2003; Fredensborg and Poulin, 2005). Prolonged larval growth, however, has associated costs, such as an increasing likelihood of natural host mortality and thus failed transmission. This trade-off between transitional size and age is the basis for many models on life-cycle evolution (Rowe and Ludwig, 1991; Stearns, 1992; Berrigan and Koella, 1994; Abrams et al. 1996; Day and Rowe, 2002; Iwasa and Wada, 2006). If a large larval size is very advantageous, then continued growth may be worth the risk, perhaps even after parasites have reached an infective stage. Under these conditions, delayed host manipulation may be a favourable strategy.

In this study, we investigated the relationship between the larval size of an acanthocephalan (Acanthocephalus lucii) and the alteration of intermediate host colouration. Freshwater fishes are the definitive hosts of $A$. lucii, usually European perch (Perca fluviatilis). Parasites mate in the fish's intestine and eggs are released into the environment with the host's faeces. Intermediate hosts, freshwater isopods of the species Asellus aquaticus, become infected by ingesting eggs. Parasites develop in the body cavity of isopods for several weeks before they reach the infective cystacanth stage (Andryuk, 1979). Post-infectivity larval size can vary considerably in 
Table 1. Naturally collected isopods used in the analysis

(The isopods were collected in different seasons and exposed to different treatments in the laboratory.)

\begin{tabular}{|c|c|c|c|c|}
\hline Block & $\begin{array}{l}\text { Collection } \\
\text { date }\end{array}$ & $N$ (infected) & Experimental treatment & Reference* \\
\hline 1 & Sept. 2005 & $148(58)$ & Approximately 1 week at $17^{\circ} \mathrm{C}, 18 \mathrm{~h}$ light & 1 \\
\hline 2 & Sept. 2005 & $84(42)$ & Less than 1 week at $17^{\circ} \mathrm{C}, 18 \mathrm{~h}$ light & 1 \\
\hline 3 & Oct. 2005 & $69(27)$ & Eight weeks observation at $17^{\circ} \mathrm{C}, 18 \mathrm{~h}$ light & 1 \\
\hline 4 & May 2006 & $40(16)$ & Two weeks observation at $17^{\circ} \mathrm{C}, 18 \mathrm{~h}$ light & 2 \\
\hline 5 & Aug. 2006 & $55(29)$ & Two weeks observation at $17^{\circ} \mathrm{C}, 18 \mathrm{~h}$ light & 2 \\
\hline 6 & Oct. 2006 & $68(31)$ & Two weeks observation at $17^{\circ} \mathrm{C}, 18 \mathrm{~h}$ light & 2 \\
\hline 7 & Aug. 2006 & $52(26)$ & $\begin{array}{l}\text { Four weeks acclimation to } 17^{\circ} \mathrm{C}, 18 \mathrm{~h} \text { light, } \\
\text { then } 2 \text { weeks observation under same conditions }\end{array}$ & 2 \\
\hline 8 & Aug. 2006 & $55(28)$ & $\begin{array}{l}\text { Four weeks acclimation to } 11^{\circ} \mathrm{C}, 12 \mathrm{~h} \text { light, } \\
\text { then } 2 \text { weeks observation under same conditions }\end{array}$ & 2 \\
\hline 9 & Aug. 2006 & $47(21)$ & $\begin{array}{l}\text { Four weeks acclimation to } 5^{\circ} \mathrm{C} \text {, no light, } \\
\text { then } 2 \text { weeks observation at } 17^{\circ} \mathrm{C}, 18 \mathrm{~h} \text { light }\end{array}$ & 2 \\
\hline
\end{tabular}

* 1, Benesh et al. (2008); 2, Benesh et al. (2009).

A. lucii; among female cystacanths there can be more than a 2 -fold difference between the smallest and largest individuals (Benesh and Valtonen, 2007c). Much of this variation is explained by isopod size; larger hosts harbour larger worms (Benesh and Valtonen, $2007 b, c)$. Therefore, parasites in small isopods may have a lot to gain by remaining in the host and continuing to grow mutually with it (Benesh and Valtonen, 2007a,b). The potential payoffs of remaining in isopods likely differ between parasite sexes, though. Female cystacanths are larger than males and their size increases faster as a function of isopod size, indicating that females allocate more of the available resources to growth (Benesh and Valtonen, 2007c). This suggests that a large transitional size is more important for females than males, possibly because fecundity increases with female size, whereas male reproductive success may only increase with body size under specific forms of competition (Stearns, 1992). Thus, delaying the expression of transmission-relevant traits until a larger size is reached may be particularly profitable for female worms.

As $A$. lucii reaches the cystacanth stage, the respiratory operculae of their hosts become darkly pigmented (Brattey, 1983), and this renders the overall abdominal pigmentation of infected isopods darker than that of uninfected isopods (Benesh et al. 2008). Conspicuous isopods are likely to be eaten by fish (Hargeby et al. 2004, 2005), so the modified colouration of infected isopods presumably increases their predation risk (Brattey, 1983; Seppälä et al. 2008). Although altered host colouration appears related to parasite transmission, a direct link has not been established. This caveat deserves mention because a recent study found no relationship between intermediate host appearance and predation risk in a different acanthocephalan (Kaldonski et al. 2009). Here we test (1) if there is a relationship between parasite size and host colouration and (2) whether this pattern differs between male and female parasites. The main analysis was conducted with naturally infected isopods. However, natural infections can be problematic, as infection is not a randomly assigned treatment. Thus, the relationship between colouration and parasite size was also investigated in a group of experimentally infected isopods.

\section{MATERIALS AND METHODS}

\section{Naturally infected isopods}

Isopods were collected in 2005 and 2006 from Lake Jyväsjärvi, Central Finland $\left(62^{\circ} 14^{\prime} \mathrm{N} 25^{\circ} 44^{\prime} \mathrm{E}\right)$ for use in various other experiments (Table 1). At the end of all experiments, live isopods were frozen in lake water at $-20{ }^{\circ} \mathrm{C}$. At a later date, isopods were thawed and individually photographed with a Nikon Coolpix 4500 digital camera (light conditions and camera settings were described by Benesh et al. (2008)). After photographs were taken, isopods were measured to the nearest $0.5 \mathrm{~mm}$ and then dissected to determine infection status (presence/absence of A. lucii; number and sex of cystacanths). Worms reach an advanced state of development in isopods, so their sex can be easily established based on whether there are testes or ovarian balls in the body cavity. Cystacanths were placed in refrigerated tap water to relax and extend. The length and width of all cystacanths were measured to the nearest $0.01 \mathrm{~mm}$ using an ocular micrometer on a light microscope. Worms were considered cylindrical in shape, so cystacanth volume $\left(\mathrm{mm}^{3}\right)$ was calculated with the equation $\left(\pi l w^{2}\right) / 4$ where $l$ is worm length and $w$ is worm width. Additionally, a subsample of worms $(n=116)$ were dried at $60{ }^{\circ} \mathrm{C}$ for $3-4 \mathrm{~h}$ and then weighed to the nearest $\mu \mathrm{g}$ on a microbalance (Sartorius, SE MA $2 \cdot 1 \mathrm{~g}$ ). 


\section{Host size - parasite size relationship}

Using a subset of the isopods listed in Table 1, Benesh and Valtonen $(2007 c)$ showed that, in singlecystacanth infections, the slope of the correlation between cystacanth size and isopod size was higher for female worms than for males. Because this growth pattern is a major assumption for our hypothesis of sexually-divergent manipulation strategies, the relationship between host size and parasite size was checked using all the collected isopods that harboured a single cystacanth. An analysis of covariance (ANCOVA) was performed with parasite volume as dependent variable, worm sex as a fixed factor, and isopod size as a covariate. A second ANCOVA using parasite dry mass instead of volume was also performed. Mass and volume measurements need not give identical results, e.g. if sexual organs (testes $v s$ ovarian balls) have different weights.

\section{Analysis of isopod colouration}

Photographs of whole isopods were analysed using Adobe Photoshop 7.0 software (Adobe Systems Inc., San Jose, CA, USA). The analysis of whole-isopod photographs was described previously (Benesh et al. 2008). Briefly, all pictures were converted to greyscale and reflectance values for the first, fourth, and seventh segments were averaged to give a mean value for body pigmentation. A reflectance value for the abdomen was also calculated. The scale of reflectance in the software ranged between 0 (black, $100 \%$ saturation) and 255 (white, $100 \%$ reflectance). Histograms of reflectance of individual pixels within the analysed areas resembled a normal distribution, so the mean value of reflectance from each area was taken as a measure of colouration. Reflectance values ranged from $41 \cdot 2$ to $126 \cdot 2$ for body colouration and $32 \cdot 5$ to $142 \cdot 3$ for abdominal colouration. This method was highly repeatable (Benesh et al. 2008).

Isopods were either uninfected $(n=340)$, infected with a single male cystacanth $(n=135)$, or infected with a single female cystacanth $(n=143)$. A number of isopods harboured 2 or more cystacanths $(n=44)$. These multiply infected isopods tended to be larger than average (one-sample t-test against overall mean isopod size, $\left.\mathrm{t}_{43}=4 \cdot 54, P<0 \cdot 0001\right)$. As the upper portion of the host size distribution was overrepresented, size by colouration correlations for multiply infected isopods may not be comparable to singly infected and uninfected isopods, so they were excluded from the analysis. Also, the few isopods harbouring small, uninfective parasites $(n=11)$ were excluded from the data.

The first and main statistical analysis compared the colouration of uninfected and infected isopods (split by worm sex). Both isopod body and abdominal colouration were evaluated with ANCOVA. Infection status and isopod sex were fixed factors and isopod size was used as a covariate. Because isopods were collected at different times and kept under different lab conditions, an experimental 'block' factor was also included in the model (see Table 1). Interactions between 'block' and other factors were not assessed because of the low sample sizes for some subgroups in some blocks (i.e. there were too few female isopods, too few isopods with a male cystacanth, etc.). However, Benesh et al. (2009) found that the effect of infection on colouration did not vary with season or light/temperature treatment, suggesting that any interaction effects are weak. All other interactions were initially included in the model. Non-significant interactions were sequentially removed to reduce model complexity.

A second, subanalysis assessed whether parasite size affects host colouration, and thus involved only infected isopods. The most parsimonious ANCOVA models (i.e. with non-significant interactions removed) from the first analysis were taken as a basis for the second analysis. Parasite size was added as a covariate to these base models and its main effect and interaction effects were checked. This analysis, therefore, assessed whether parasite size explains any additional variation in isopod colouration not covered by the main model.

\section{Experimental infection and opercular colouration}

To check the validity of the results obtained with naturally infected isopods, colouration changes were also observed in experimentally infected isopods. Isopods were collected in August 2005 with a dipnet from Niemijärvi, a small pond in central Finland $\left(62^{\circ} 12^{\prime} \mathrm{N} 25^{\circ} 45^{\prime} \mathrm{E}\right)$ in which the only fish species present is Carassius carassius, the crucian carp. Thus, all isopods were uninfected because the definitive host of the parasite is not present in the pond. Isopods were either exposed to fish faeces containing parasite eggs or sham-exposed with distilled water (the details of this infection have been reported by Benesh and Valtonen (2007a)). Isopods were observed for 101 days before any remaining animals were killed and dissected. Nearly all exposed isopods were infected with multiple parasites, and the number and size of all parasites were recorded from each isopod. The average infection intensity for the isopods used in this analysis was $17 \cdot 24$ (s.D. $\pm 8 \cdot 35$ ). For most of the isopods that died 75 days or more postexposure, the respiratory operculae were collected and stored in $70 \% \mathrm{EtOH}$. Opercula were dehydrated through an $\mathrm{EtOH}$ series, and then mounted, ventral side up, on microscope slides in Euparal medium. The opercula were photographed at $40 \times$ magnification using a Nikon Coolpix 4500 camera (scene mode: close up, focal length: $96 \mathrm{~mm}$, aperture: F5.4, shutter speed: 1/500, sensitivity: ISO100, image size: $1600 \times 1200$ pixels, image quality: fine, focus mode: auto) attached to a light microscope with an 
M28 $\times 0.75$ digital coupler (Thales Optem Inc., Fairport, NY, USA). Opercular colouration was analysed in a similar manner as described above for whole isopod photographs. Reflectance was measured from a circular area (400-pixel diameter) in the middle of both the left and right operculae, and these values were averaged to give a mean reflectance value for each isopod. A subsample of operculae was photographed a second time to establish that the method was repeatable $\left(n=29, \mathrm{R}=0 \cdot 99, \mathrm{~F}_{28,29}=271\right.$, $P<0 \cdot 001)$.

Opercular colouration for unexposed controls $(n=$ 34) was compared to that of exposed, infected isopods $(n=45)$ with a Mann-Whitney U-test. A multiple regression model was then used to examine how the characteristics of the parasite infrapopulation affected opercular colouration. The total worm volume harboured by an infected isopod was included as a predictor. However, the distribution of parasite volume among individuals may also be important, i.e. pigment alteration may differ between a host with a few large worms and one with several small worms. In hosts harbouring a few big parasites, the average volume of worms, relative to the total, should increase. Residuals were taken of a regression of average worm size on total worm size. These residuals represent the variation in average worm size independent of the total parasite volume. For example, positive residuals (a large average volume relative to the total) characterize hosts in which the total parasite volume is concentrated into fewer individuals. Using residuals as a measure of average worm size in the regression model also circumvented the problem of collinearity (Mason and Perreault, 1991). Because $A$. lucii is sexually dimorphic, the sex ratio of the infrapopulation may affect how worm volume is distributed among individual parasites, so log sex ratio was also included in the regression model. The operculae from most infected isopods $(77 \cdot 8 \%)$ were collected 94-101 days post-exposure, so parasite age varied little and was not included in the model.

All statistical analyses were performed with SPSS 14.0 (SPSS Inc., Chicago, Illinois) software.

\section{RESULTS}

\section{Host size-parasite size relationship}

In natural infections, the relationship between parasite volume and isopod size was dependent on worm sex (ANCOVA, isopod size $\times$ worm sex, $\left.\mathrm{F}_{1,274}=84 \cdot 0, P<0 \cdot 0001\right)$. In accordance with the results of Benesh and Valtonen (2007c), female cystacanth size increased more steeply with host size than male size (Fig. 1A). The same pattern was observed when parasite dry mass was used (ANCOVA, isopod size $\times$ worm sex, $\left.F_{1,112}=34 \cdot 4, P<0 \cdot 0001\right)$, although the difference between males and females was not as pronounced (Fig. 1B).
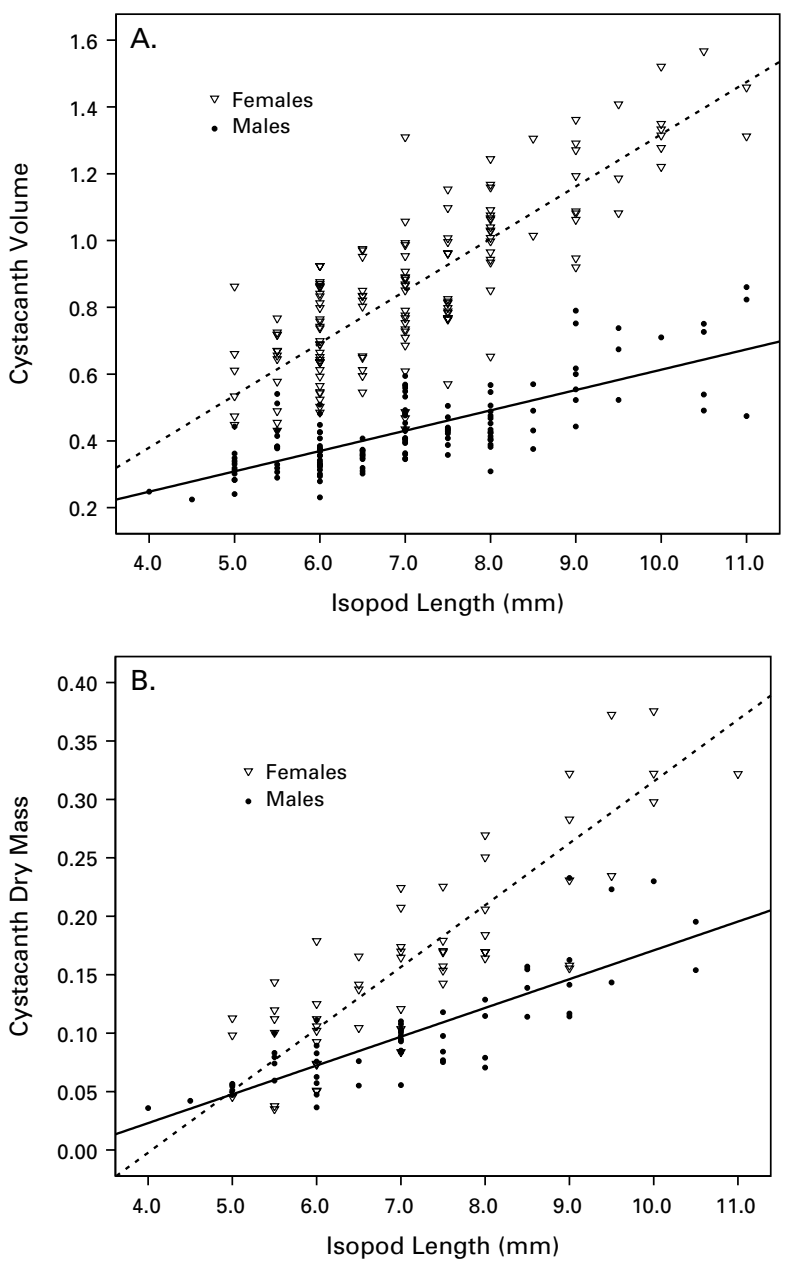

Fig. 1. The relationship between isopod size and parasite size measured as (A) volume $\left(\mathrm{mm}^{3}\right)$ or as (B) dry mass (mg). Male and female cystacanths came from singly infected isopods collected from the field.

\section{Isopod colouration in naturally collected isopods}

After removing non-significant interactions, the terms included in the ANCOVAs were identical for body and abdominal coloration (from here $\mathrm{BC}$ and $\mathrm{AC}$, respectively; Table 2). For both $\mathrm{BC}$ and $\mathrm{AC}$, there was a significant interaction between infection status and isopod size $\left(\mathrm{F}_{2,609}=4 \cdot 14, P=0 \cdot 016\right.$ and $\mathrm{F}_{2,609}=8 \cdot 21, P<0 \cdot 001$, respectively; Table 2 ). This is a violation of the 'homogeneity of regressions' assumption of ANCOVA, i.e. the relationship between the dependent variable (colouration) and the covariate (isopod size) differs among levels of the factor (infection status). Consequently, the estimated main effect of infection status may be biased. Thus, uninfected, male-infected, and female-infected isopods are only compared within the context of isopod size. The slope of the $\mathrm{BC}$ by size relationship was steepest for isopods infected with a female cystacanth, but the between-group differences were small (Fig. 2A). The interaction was clearer for AC. The difference between infected and uninfected isopods increased with isopod size, because the AC of 
Table 2. Summary of ANCOVA analyses evaluating isopod colouration

(Isopods were classified as uninfected, infected with a male cystacanth, or infected with a female cystacanth. The block factor refers to the different experimental treatments listed in Table 1. Non-significant interaction terms $(P>0.05)$ were sequentially removed from the ANCOVAs to produce more parsimonious models.)

\begin{tabular}{lrrr}
\hline \hline & F & D.F. & \multicolumn{1}{c}{$P$} \\
\hline Body colouration & & & \\
$\quad$ Infection status & $5 \cdot 77$ & 2 & $0 \cdot 003$ \\
$\quad$ Isopod sex & $19 \cdot 70$ & 1 & $<0 \cdot 001$ \\
Block & $23 \cdot 33$ & 8 & $<0 \cdot 001$ \\
$\quad$ Isopod size & $143 \cdot 54$ & 1 & $<0 \cdot 001$ \\
$\quad$ Infection status $\times$ Isopod size & $4 \cdot 14$ & 2 & $0 \cdot 016$ \\
$\quad$ Isopod sex $\times$ Isopod size & $32 \cdot 57$ & 1 & $<0 \cdot 001$ \\
$\quad$ Error & & 609 & \\
Abdominal colouration & & & \\
$\quad$ Infection status & $8 \cdot 28$ & 2 & $<0 \cdot 001$ \\
$\quad$ Isopod sex & $8 \cdot 37$ & 1 & $0 \cdot 004$ \\
$\quad$ Block & $20 \cdot 10$ & 8 & $<0 \cdot 001$ \\
Isopod size & $89 \cdot 59$ & 1 & $<0 \cdot 001$ \\
$\quad$ Infection status $\times$ Isopod size & $8 \cdot 21$ & 2 & $<0 \cdot 001$ \\
$\quad$ Isopod sex $\times$ Isopod size & $11 \cdot 21$ & 1 & $0 \cdot 001$ \\
$\quad$ Error & & 609 & \\
\hline
\end{tabular}

infected isopods became conspicuously darker in larger isopods (Fig. 2B). There was also a difference between worm sexes. Small isopods infected with a male cystacanth tended to have darker AC than those infected with a female cystacanth, but in larger isopods AC was similar (Fig. 2B). For BC and AC, there was a significant interaction between isopod sex and size (Table 2), because female isopods were slightly darker than males when large but not when small.

Adding parasite size to the ANCOVAs, either as volume or mass, did not produce any new results. For both $\mathrm{AC}$ and $\mathrm{BC}$, worm size and all its interactions were non-significant (all $P>0 \cdot 05$ ), indicating that parasite size did not explain any additional variation in host colouration beyond that described in the main analysis.

\section{Opercular colouration in experimentally infected isopods}

The operculae of exposed, infected isopods were darker than those of control isopods (Mann-Whitney U-test, $\mathrm{Z}=-5 \cdot 13, P<0 \cdot 001)$. Hosts harbouring a larger total parasite volume tended to have darker operculae (standardized beta $=-0.39, \mathrm{t}_{41}=-3 \cdot 02$, $P=0 \cdot 004$; Fig. 3A). Moreover, a large average worm volume, relative to the total, was also associated with darker operculae (standardized beta $=-0.41, \mathrm{t}_{41}=$ $-3 \cdot 20, P=0 \cdot 003$; Fig. $3 \mathrm{~B})$, which suggests that isopods with a few large worms had more severely altered pigmentation than those with many small worms. The infrapopulation sex ratio did not affect
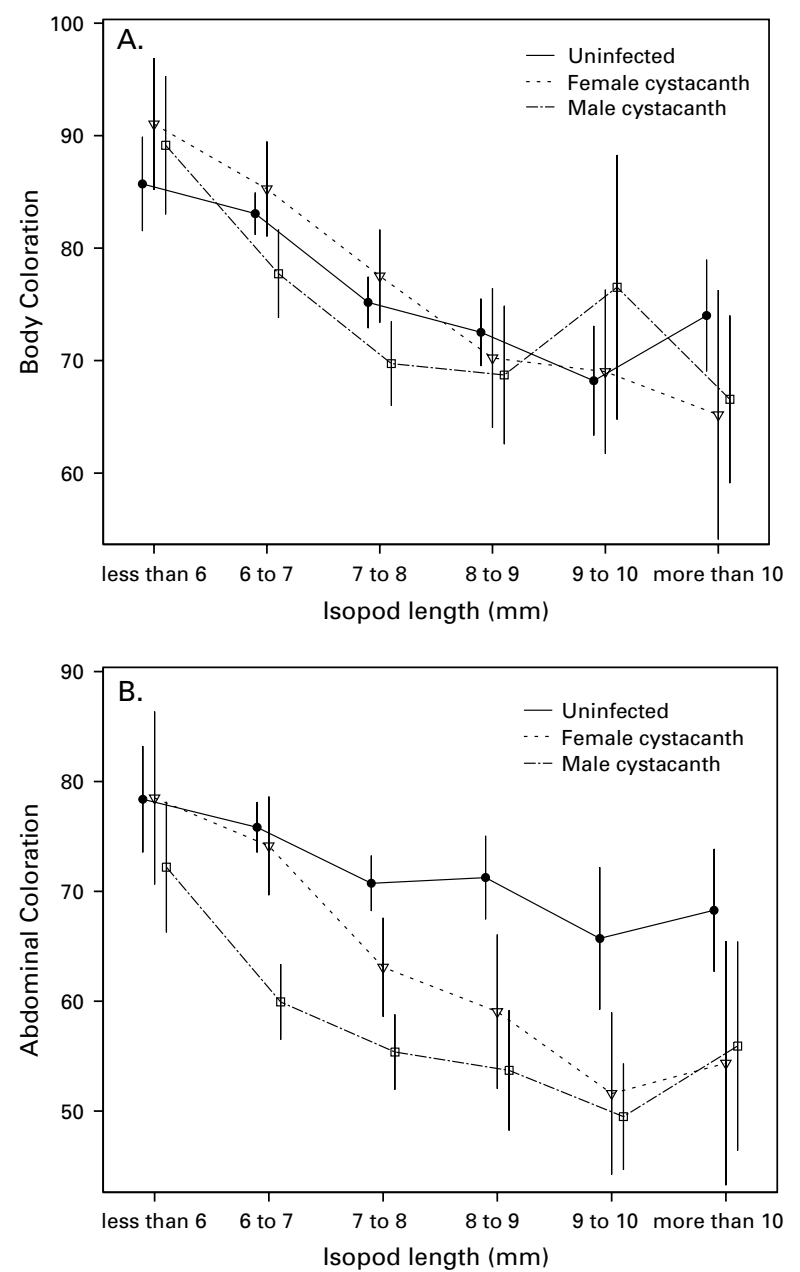

Fig. 2. Body (A) and abdominal (B) colouration as a function of isopod length. The data are separated into uninfected isopods (circles, solid line), isopods infected with a single female cystacanth (open triangles, dashed line), and isopods infected with a single male cystacanth (open squares, broken line). Statistical analyses treated isopod size as a continuous variable, but trends were difficult to discern in a scatter-plot due to the extensive overlap among individual data points. Thus, for clarity, isopod size is plotted as a categorical variable.

Colouration is lighter at higher values on the scale.

Bars represent the $95 \% \mathrm{CI}$.

opercular colouration (standardized beta $=-0 \cdot 05$, $\left.\mathrm{t}_{41}=-0 \cdot 35, P=0 \cdot 73\right)$.

\section{DISCUSSION}

The alteration of isopod colouration only occurs after parasites become cystacanths (Brattey, 1983). However, maximum host alteration was not achieved immediately after attaining the cystacanth stage. In both naturally and experimentally infected isopods, larger parasites more strongly altered host pigmentation. In the naturally infected isopods, abdominal colouration was darkest, relative to uninfected isopods, in large hosts that harboured bigger worms. Likewise, a large total parasite volume was associated 

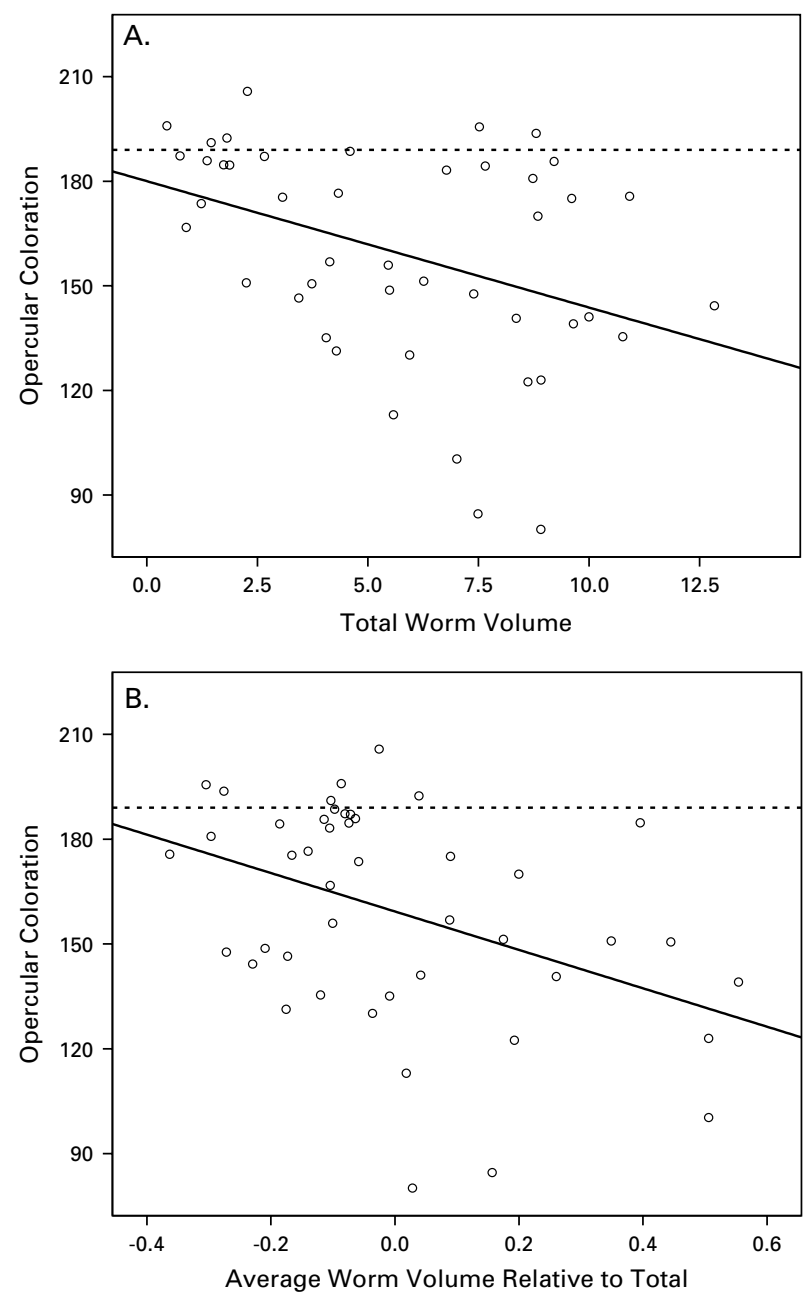

Fig. 3. The relationship between opercular coloration and (A) the total parasite volume $\left(\mathrm{mm}^{3}\right)$ harboured by experimentally infected isopods and (B) the residuals of a regression of average parasite volume against total parasite volume. Positive residuals represent hosts with a large average parasite volume relative to the total, i.e. the total parasite volume is concentrated into fewer individuals. The solid lines are the least squares regression lines for the data, while the dashed lines represent the mean opercular colouration of unexposed, control isopods. Colouration is lighter at higher values on the scale.

with darker opercular colouration in experimentally infected isopods, particularly when it was distributed among fewer individual worms. Moreover, the experimental isopods were sampled at about the same time, so the relationship between parasite size and host colouration was not confounded by potential effects of parasite age. Parasite age might also influence host manipulation, but we could not assess this, as there was little variation in parasite age in our experimental data. Evaluating the relative importance of parasite size versus age requires independent variation in each, e.g. parasites could be sampled at different ages after they had been growing at different rates.
Though larger, more modified hosts harboured larger parasites, parasite size was not a significant covariate in the ANCOVA analyses conducted with the field-collected isopods. This was probably because parasite size did not explain any additional variation in colouration beyond that described by host size. That is, parasites that were large (or small) relative to their host's size did not modify host pigmentation more (or less) extensively. Modification of other host traits may also increase as parasites grow, though imperfectly. For example, from late summer to the following spring, the size of isopods and parasites increases, as does the alteration of host hiding behaviour (Benesh et al. 2009). However, host behaviour is not clearly modified in late autumn, even though isopods are of a similar size to those collected in spring (Benesh et al. 2009). Thus, for both host behaviour and colouration, there is a positive, but imperfect correlation between parasite size and trait alteration. Similar trends have been noted in tapeworms in their fish second intermediate hosts. For example, Brown et al. (2001) found that fish infected with larger Ligula intestinalis plerocercoids had more altered habitat choice, and Ness and Foster (1999) found larger Schistocephalus solidus in demelanized sticklebacks. Size-dependent manipulation may be an adaptive strategy, because, as parasites grow larger, the relative benefits of remaining in the intermediate host decrease while the potential costs increase. At some point, the amount of additional larval growth possible diminishes due to space or resource constraints (Michaud et al. 2006; Benesh and Valtonen, $2007 b$; Shostak et al. 2008). Concomitantly, the probability of natural host mortality presumably increases. Therefore, the profitability of transmission, and by association host manipulation, is likely to increase as parasites grow over time.

Many acanthocephalans are sexually dimorphic as cystacanths (e.g. Amin et al. 1980; Oetinger and Nickol, 1981; Steinauer and Nickol, 2003), presumably because the benefits of a large larval size are more pronounced for females than males (Benesh and Valtonen, 2007c). This sexual dimorphism might favour divergent manipulation strategies. Oetinger and Nickol (1981), however, did not observe differences in the "pigment dystrophy" exhibited by isopods infected with male or female Acanthocephalus dirus cystacanths. The hiding behaviour of isopods infected with a male or female A. lucii cystacanth also does not seem to differ (Benesh, unpublished data). In this study, male worms appeared to alter isopod abdominal colouration more extensively than female worms in small hosts, but in larger hosts this difference disappeared. Because female cystacanth size increases rapidly with host size, females in small hosts may have more to gain than males by remaining in and growing mutually with the host (infection does not impair isopod growth, Benesh and Valtonen, $2007 a$; Hasu 
et al. 2007). The more extensive modification of small hosts by male parasites may thus reflect their relatively higher incentive to be transmitted. By contrast, in larger isopods, neither male nor female parasites may profit from staying in the intermediate host, favouring similar, high levels of host modification by both sexes. Sexually divergent manipulation strategies could also arise via differences in resource availability, assuming manipulation entails energetic costs. Because male parasites invest less in growth, they may have more resources available to allocate toward modifying host pigmentation. However, the largest colouration difference between male- and female-cystacanth infections was observed in small isopods when parasite size dimorphism is relatively low and resource pools are presumably similar. This suggests that the sex-specific manipulation strategies stem from different optimal sizes for transmission rather than dissimilarities in resource availability.

Visual-based predation by fish is likely to be a selective force maintaining cryptic colouration in A. aquaticus (Hargeby et al. 2004, 2005), so the conspicuously darker abdominal pigmentation of naturally infected isopods probably increases their susceptibility to predation by fish definitive hosts (Brattey, 1983; Seppälä et al. 2008). If large heavily manipulated hosts harbouring large parasites are taken more easily by predators, then parasite abundance may be higher in hosts of medium size. Consistent with this prediction, natural $A$. lucii abundance peaks in intermediate-sized isopods and is reduced in large isopods (Brattey, 1986). Although a number of processes can produce this pattern (e.g. age-dependent exposure, Duerr et al. 2003), it would be interesting to see if other helminths with similar distributions in their intermediate host populations (Thomas et al. 1995; Rousset et al. 1996; Outreman et al. 2007) also increase host manipulation as they grow. Unlike $A$. lucii, however, many parasites exhibit relatively fixed growth strategies, i.e. after developing to an infective stage, growth stops. For these species, there may be no additional benefits, only costs, associated with remaining in the intermediate host after infectivity is reached, so discrete changes in the level of host manipulation might be favoured. Different parasite growth patterns may, thus, lead to different host manipulation strategies.

Jukka Jokela and two reviewers gave helpful comments on an earlier version of this manuscript. D.P.B. was supported by the Biological Interactions Graduate School at the University of Turku and O.S. by the Academy of Finland.

\section{REFERENCES}

Abrams, P. A., Leimar, O., Nylin, S. and Wiklund, C. (1996). The effect of flexible growth rates on optimal sizes and development times. American Naturalist 147, 381-395.
Amin, O. M., Burns, L. A. and Redlin, M. J. (1980).

The ecology of Acanthocephalus parksidei (Acanthocephala: Echinorhynchidae) in its isopod intermediate host. Proceedings of the Helminthological Society of Washington 47, 37-46.

Andryuk, L. V. (1979). Developmental cycle of the thorny-headed worm, Acanthocephalus lucii (Echinorhynchidae). Parazitologiia 13, 530-539 (in Russian).

Benesh, D. P. and Valtonen, E. T. $(2007 a)$. Effects of Acanthocephalus lucii (Acanthocephala) on intermediate host survival and growth: implications for exploitation strategies. Fournal of Parasitology 93, 735-741.

Benesh, D. P. and Valtonen, E. T. $(2007 b)$. Proximate factors affecting the larval life history of Acanthocephalus lucii (Acanthocephala). Fournal of Parasitology 93, 742-749.

Benesh, D. P. and Valtonen, E. T. $(2007 c)$. Sexual differences in larval life history traits of acanthocephalan cystacanths. International Fournal for Parasitology 37, 191-198.

Benesh, D. P., Valtonen, E. T. and Seppälä, O. (2008). Multidimentionality and intra-individual variation in host manipulation by parasites. Parasitology 135, 617-626.

Benesh, D. P., Hasu, T., Seppälä, O. and Valtonen, E. T. (2009). Seasonal changes in host phenotype manipulation by an acanthocephalan: time to be transmitted? Parasitology 136, 219-230.

Berrigan, D. and Koella, J. C. (1994). The evolution of reaction norms: simple models for age and size at maturity. Fournal of Evolutionary Biology 7, 549-566.

Bethe1, W. M. and Holmes, J. C. (1974). Correlation of altered evasive behavior in Gammarus lacustris (Amphipoda) harboring cystacanths of Polymorphus paradoxus (Acanthocephala) with the infectivity to the definitive host. Fournal of Parasitology 60, $272-274$.

Brattey, J. (1983). The effects of larval Acanthocephalus lucii on the pigmentation, reproduction and susceptibility to predation of the isopod Asellus aquaticus. Fournal of Parasitology 69, 1172-1173.

Brattey, J. (1986). Life history and population biology of larval Acanthocephalus lucii (Acanthocephala: Echinorhynchidae) in the isopod Asellus aquaticus. Fournal of Parasitology 72, 633-645.

Brown, S. P., Loot, G., Grenfell, B. T. and Guégan, J. F. (2001). Host manipulation by Ligula intestinalis: accident or adaptation? Parasitology 123, 519-529.

Day, T. and Rowe, L. (2002). Developmental thresholds and the evolution of reaction norms for age and size at life history transitions. American Naturalist 159, 338-350.

Duerr, H. P., Dietz, K. and Eichner, M. (2003). On the interpretation of age-intensity profiles and dispersion patterns in parasitological surveys. Parasitology 126, 87-101.

Franceshi, N., Bauer, A., Bollache, L. and Rigaud, T. (2008). The effects of parasite age and intensity on variability in acanthocephalan-induced behavioural manipulation. International Fournal for Parasitology 38, 1161-1170.

Fredensborg, B. L. and Poulin, R. (2005). Larval helminthes in intermediate hosts: does competition 
early in life determine the fitness of adult parasites? International Fournal for Parasitology 35, 1061-1070.

Hargeby, A., Johansson, J. and Ahnesjö, J. (2004). Habitat-specific pigmentation in a freshwater isopod: adaptive evolution over a small spatiotemporal scale. Evolution 58, 81-94.

Hargeby, A., Stoltz, J. and Johansson, J. (2005). Locally differentiated cryptic pigmentation in the freshwater isopod Asellus aquaticus. Fournal of Evolutionary Biology 18, 713-721.

Hasu, T., Holmes, J. C. and Valtonen, E. T. (2007). Isopod size (Asellus aquaticus) and acanthocephalan (Acanthocephalus lucii) infections. Fournal of Parasitology 93, 450-457.

Iwasa, Y. and Wada, G. (2006). Complex life cycle and body sizes at life-history transitions for macroparasites. Evolutionary Ecology Research 8, 1427-1443.

Kaldonski, N., Perrot-Minnot, M.-J., Dodet, R., Martinaud, G. and Cézilly, F. (2009). Carotenoid-based colour of acanthocephalan cystacanths plays no role in host manipulation. Proceedings of the Royal Society of London, B 276, 169-176.

Mason, C. H. and Perreault, W. D. (1991). Collinearity, power, and interpretation of multiple regression analysis. Fournal of Marketing Research 28, 268-280.

Michaud, M., Milinski, M., Parker, G. A. and Chubb, J. C. (2006). Competitive growth strategies in intermediate hosts: experimental tests of a parasite life-history model using the cestode, Schistocephalus solidus. Evolutionary Ecology 20, 39-57.

Moore, J. (2002). Parasites and the Behavior of Animals. Oxford University Press, Oxford, UK.

Ness, J. H. and Foster, S. A. (1999). Parasite-associated phenotype modifications in threespine stickleback. Oikos 85, 127-134.

Oetinger, D. F. and Nickol, B. B. (1981). Effects of acanthocephalans on pigmentation of freshwater isopods. Fournal of Parasitology 67, 672-684.

Outreman, Y., Cézilly, F. and Bollache, L. (2007). Field evidence of host size-dependent parasitism in two manipulative parasites. Fournal of Parasitology 93, 750-754.

Parker, G. A., Chubb, J. C., Roberts, G. N., Michaud, M. and Milinski, M. (2003). Optimal growth strategies of larval helminths in their intermediate hosts. Fournal of Evolutionary Biology 16, 47-54.
Poulin, R., Curtis, M. A. and Rau, M. E. (1992). Effects of Eubothrium salvelini (Cestoda) on the behaviour of Cyclops vernalis (Copepoda) and its susceptibility to fish predators. Parasitology 105, 265-271.

Pulkkinen, K., Pasternak, A. F., Hasu, T. and Valtonen, E. T. (2000). Effect of Triaenophorus crassus (Cestoda) infection on behavior and susceptibility to predation of the first intermediate host Cyclops strenuous (Copepoda). Fournal of Parasitology 86, 664-670.

Rosen, R. and Dick, T. A. (1983). Development and infectivity of the procercoid of Triaenophorus crassus Forel and mortality of the first intermediate host. Canadian Fournal of Zoology 61, 2120-2128.

Rousset, F., Thomas, F., de Meeûs, T. and Renaud, F. (1996). Inference of parasite-induced host mortality from distributions of parasite loads. Ecology 77, 2203-2211.

Rowe, L. and Ludwig, D. (1991). Size and timing of metamorphosis in complex life cycles: time constraints and variation. Ecology 72, 413-427.

Seppälä, O., Karvonen, A. and Valtonen, E. T. (2005). Manipulation of fish host by eye flukes in relation to cataract formation and parasite infectivity. Animal Behaviour 70, 889-894.

Seppälä, O., Valtonen, E. T. and Benesh, D. P. (2008). Host manipulation by parasites in the world of dead-end predators: adaptation to enhance transmission? Proceedings of the Royal Society of London, B 275, 1611-1615.

Shostak, A. W., Walsh, J. G. and Wong, Y. C. (2008). Manipulation of host food availability and use of multiple exposures to assess the crowding effect on Hymenolepis diminuta in Tribolium confusum. Parasitology 135, 1019-1033.

Stearns, S. C. (1992). The Evolution of Life Histories. Oxford University Press, Oxford, UK.

Steinauer, M. L. and Nickol, B. B. (2003). Effect of cystacanth body size on adult success. Fournal of Parasitology 89, 251-254.

Thomas, F., Adamo, S. and Moore, J. (2005). Parasitic manipulation: where are we and where should we go? Behavioural Processes 68, 185-199.

Thomas, F., Renaud, F., Rousset, F., Cézilly, F. and de Meeûs, T. (1995). Differential mortality of two closely related host species induced by one parasite. Proceedings of the Royal Society of London, B 260, 349-352. 